\title{
A experiência emocional atualizadora em Gestalt- terapia de curta duração
}

\section{Self-actualization emotional experience in short-term Gestalt- therapy}

\author{
Ênio Brito Pinto * \\ Professor Titular do Instituto de Gestalt de São Paulo/IGT-SP - São Paulo, SP, \\ Brasil \\ Professor do Instituto Sedes Sapientae - São Paulo, SP, Brasil \\ Professor dolnstituto Brasileiro Interdisciplinar de Sexologia e Medicina \\ Psicossomática/ISEXP - São Caetano do Sul, SP, Brasil \\ Professor da Faculdade de Medicina do ABC - Santo André, SP, Brasil \\ Professor do Centro Universitário das Faculdades Metropolitanas Unidas/UniFMU - \\ São Paulo, SP, Brasil
}

\begin{abstract}
Resumo
Apresenta-se e se discute o conceito, de Alexander, de experiência emocional corretiva, sob a ótica da abordagem gestáltica. Propõe-se que em Gestalt-terapia se deva falar em experiência emocional atualizadora. Discute-se a noção de neurose e de psicopatologia em Gestalt-terapia, bem como as implicações desses conceitos no processo de Gestalt-terapia de Curta Duração.

Palavras-chave: Experiência emocional corretiva, Experiência emocional atualizadora, Gestalt-terapia de Curta Duração, Relação terapêutica, Autoatualização.
\end{abstract}

\begin{abstract}
This article arose from the concept, from Alexander, about corrective emocional experience, in the view from the Gestalt Therapy approach. A concept of Self-actualization emotional experience was proposed, through the discussion of neurosis and psychopathology in Short-term Gestalt Therapy as psychotherapeutical working.

Keywords: Corrective emotional experience, Self-actualization emotional experience, Short-term Gestalt therapy, therapeutic relationship, Selfactualization.
\end{abstract}


Não existe isso a que chamam de integração total. A integração nunca se completa; a maturação nunca se completa.

Ela é um processo sempre em andamento.

PERLS (1977, p. 95)

É cada vez maior a demanda, nos dias de hoje, por trabalhos terapêuticos que sejam úteis em um tempo relativamente curto. Quer seja pelo alto preço de uma terapia de longo prazo, quer seja pelo estilo de vida que caracteriza nossa apressada cultura nesse começo de século XXI, quer seja pela maior possibilidade de se dar acesso aos recursos da psicoterapia às pessoas de menos poder e de menor poder aquisitivo, quer seja porque hoje há mais pessoas que podem se beneficiar de intervenções psicoterapêuticas rápidas, quer seja porque essa é a modalidade de psicoterapia pela qual os planos de saúde aceitam pagar, o fato é que há um espaço enorme e crescente para esse tipo de trabalho. Em Gestalt-terapia há ainda muito a se desenvolver sobre esse tema, e esse artigo é a uma forma de colaborar com esses estudos.

Para quem estuda as fundamentações teóricas sobre os trabalhos psicoterapêuticos de duração mais curta, há alguns conceitos que atravessam as diversas correntes teóricas, sendo aplicáveis, com algumas adaptações, a todas elas; são, geralmente, conceitos provenientes das primeiras teorizações sobre as psicoterapias breves. Um desses conceitos seminais para os trabalhos de curta duração foi formulado pelo psicanalista Franz Alexander, em um livro que organizou, em 1946, com Thomas French, "Terapêutica Psicanalista". Trata-se daquilo que Alexander denominou de "experiência emocional corretiva". Minha intenção aqui é apresentar e discutir esse conceito de Alexander sob a ótica da abordagem gestáltica, ponderando sobre como as idéias de Alexander podem ser aproveitadas em um trabalho de Gestalt-terapia de Curta Duração.

Quando se trata de trabalho psicoterapêutico feito em um tempo relativamente curto, o nome que se dará a essa atividade dependerá da abordagem teórica que fundamenta o saber do terapeuta. No entanto, independentemente do nome, ou seja, quer se fale de psicoterapia breve, de aconselhamento psicológico, de psicoterapia de curta duração, está-se tratando de um tipo de trabalho que tem algumas características básicas. Seja um trabalho de base psicanalítica, seja um trabalho de base comportamental, seja um trabalho baseado em uma teoria fenomenológica, como é o caso da Gestalt-terapia de Curta Duração, o fato é que esse trabalho se estruturará especialmente a partir de quatro aspectos essenciais: a) o sintoma, quer dizer, a queixa trazida pelo cliente; b) a (de)limitação do olhar terapêutico, ou eleição de foco para o trabalho; c) a compreensão diagnóstica; e d) a relação terapêutica. Cada corrente 
teórica em psicoterapia compreenderá e trabalhará de uma maneira própria cada um desses quatro aspectos, mas não há a possibilidade de uma psicoterapia de curta duração que não os leve em delicada conta.

Daqui por diante, discutirei uma das faces do quarto aspecto, talvez uma das particularidades da relação terapêutica mais importantes para as psicoterapia de curta duração: o fato de essa relação possibilitar ao cliente uma experiência emocional de crescimento. Esse tema, levantado, como já vimos, por Alexander (1965), é bastante desenvolvido nas teorizações, psicanalíticas ou não, sobre as psicoterapias mais breves (conforme BELLAK; SMALL, BRAIER, FERREIRA-SANTOS, FIORINI, GILLIÉRON, LEMGRUBER, YOSHIDA, dentre outros) Alexander defendeu que, numa psicoterapia breve, a relação terapêutica deva ser uma experiência emocional corretiva. A partir de um ponto de vista gestáltico, embora a premissa de Alexander possa ser, em parte, incorporada, ela precisa ser, em parte, reelaborada. Para o gestalt-terapeuta, a relação terapêutica não é uma experiência emocional corretiva, mas uma experiência emocional atualizadora.

A experiência emocional vivida pelo cliente em Gestalt-terapia de curta duração não poderia ser chamada de experiência emocional corretiva, como se usa na maioria das abordagens psicanalíticas em psicoterapia breve, porque na abordagem gestáltica não se parte do princípio de que algo deva ser corrigido no cliente, mas, sim, de que algo precisa ser atualizado para que ele volte a desenvolver-se, atualizando continuamente seus potenciais. Se em Gestalt-terapia se trabalha com a noção do auto-atualização e com o conceito de ajustamento criativo e a conseqüente idéia de que mesmo as reações neuróticas ou psicóticas são ajustamentos criativos, seria incoerente pensarmos em corrigir aquilo que foi criativo e vital um dia. $O$ problema atual do cliente é que aquela solução criativa se cristalizou e agora precisa ser atualizada, não corrigida. Ela não foi um erro, muito antes pelo contrário.

A distinção que proponho aqui não é apenas um jogo ou uma mudança de palavras, mas uma posição bastante diferente quanto à compreensão diagnóstica que se faz no processo terapêutico, a qual, por sua vez, trará diferenças quanto à compreensão do sintoma, quanto à eleição do foco, quanto ao posicionamento do terapeuta diante de seu cliente. Em suma, quando compreendemos que a atualização não é uma correção, fazemos uma psicoterapia diferente, mais útil para o cliente.

Quando se fala em uma experiência emocional corretiva, parte-se de um princípio psicopatológico de que haveria uma maneira certa de se reagir às situações da vida, uma maneira que o cliente não logrou alcançar e, por isso, desenvolveu uma neurose ou uma psicose. Esse ponto de vista não faz sentido para o olhar gestáltico, por uma série 
de razões que discutirei daqui por diante. Antes, porém, de começar a discutir essa diferença do ponto de vista da Gestalt-terapia, pareceme importante compreender melhor o conceito desenvolvido por Alexander e as premissas das quais deriva este conceito.

Para compreendermos a posição de Alexander no desenvolvimento de trabalhos psicoterapêuticos breves, é importante um rápido olhar histórico, com ênfase no desenvolvimento da psicanálise, teoria de fundamento de Alexander e de início de Perls. Segundo Gillierón (2004, p. 27), Freud, depois de ponderar sobre as sugestões de Ferenczi e Rank, os quais propunham um analista mais ativo no processo, rejeita veementemente essas idéias de seus colaboradores e "recomenda novamente ao analista manter-se 'atemporal', com o intuito de chegar mais perto do inconsciente do enfermo". Essa sugestão de Freud data de 1920, ano importante para a psicanálise, pois é ali que, segundo Gillierón (2004, p. 29), delineiam-se duas correntes diferentes no movimento psicanalítico da época: uma, mais ortodoxa, cujos esforços se voltam para pesquisas metapsicológicas, dando pouca atenção às questões ambientais; outra, mais voltada para os aspectos técnicos da psicoterapia, cujos precursores serão, em especial, Ferenczi e Rank, que "optará por aprofundar o estudo da relação terapêutica." Essa segunda corrente exerceria, um pouco mais tarde, importante influência sobre Fritz Perls e sobre suas formulações para a Gestalt-terapia.

Assim é que dessa corrente de orientação mais clínica surgiram, dentre os fundadores da Sociedade Psicanalítica de Viena, alguns dos mais importantes dissidentes de Freud: Adler (que buscou um trabalho analítico mais centrado no consciente que no inconsciente, mais centrado nos conflitos atuais que nos infantis, perspectiva que influenciou profundamente o trabalho de Perls e de seus seguidores), W. Steckel (que propôs uma técnica parecida com a de Adler e "dizia pretender evitar uma infantilização dos pacientes, afirmando até que apenas os tratamentos de duração breve tinham alguma chance de sucesso" [apud GILLIERÓN, 2004, p. 35]), Jung, (que buscava uma maior atividade do terapeuta, um maior interesse pela situação atual do paciente, "a passagem ao face a face, a redução da freqüência das sessões, a tentativa de evitar a regressão" [apud GILLIERÓN, 2004, p. 36]). Além desses, e posteriores a esses, podemos colocar também Sandor Ferenczi e Otto Rank como dois dissidentes de Freud e importantes teóricos da psicoterapia breve. Quanto a Rank, segundo Yoshida (1990, p. 15), sua dissidência se deveu à defesa do conceito de will-therapy (terapia da vontade), algo muito parecido com um dos critérios fundamentais para a indicação da psicoterapia de curta duração, a motivação para mudar. Rank foi um dos principais influenciadores do trabalho de Perls, pois grande parte da orientação humanista da Gestalt-terapia se deve a algumas influências sofridas de Otto Rank, que acreditava que a primeira luta 
humana é aquela pela individuação pessoal, o que se tornou também uma das preocupações centrais da Gestalt-terapia. A idéia da resistência vista como criativa e como facilitadora de uma nova organização pessoal também advém de Rank e é capital na Gestaltterapia. A resistência não deve ser combatida, mas sim deve ser trazida à consciência do cliente e respeitada como um limite do seu agora. (RIBEIRO, 1985, p. 22)

Franz Alexander e Thomas M. French foram continuadores de Ferenczi e Rank e autores do livro Terapêutica Psicanalítica (cuja primeira edição é de 1946), marcante na história das psicoterapias breves. Os dois "propunham uma atitude francamente ativa por parte do terapeuta, [...] a fim de se evitarem regressões excessivas que terminam por exacerbar a dependência e as resistências do paciente, levando ao prolongamento desnecessário da análise". (YOSHIDA, 1990, p. 16) É nesse livro que Alexander expõe e desenvolve o princípio de experiência emocional corretiva, objeto dessas discussões que faço agora.

O conceito de Alexander fundamenta-se em uma premissa que é básica em psicanálise e que, por via disso, está também presente na maioria das abordagens em psicoterapia, inclusive na abordagem gestáltica, embora com compreensões um pouco diferentes: trata-se da idéia de que a neurose teria uma etiologia, ou seja, uma causa ou uma origem em um período anterior, geralmente na infância. Se na psicanálise esse conceito é basilar, em vista da compreensão determinista que Freud lançou sobre o ser humano, em Gestaltterapia, não encontraremos solo para essa visão determinista sobre o ser humano. Mas está presente na abordagem gestáltica a idéia de que somos uma construção ao longo do tempo, ou seja, de que o ser humano se constrói no correr da vida. Assim, a compreensão que o gestalt-terapeuta tem de seu cliente também se utiliza de concepções etiológicas. Em outros termos, podemos dizer que, em Gestaltterapia, se não somos deterministas, muito menos desprezamos a influência do passado na configuração atual de cada pessoa.

Para Alexander, há, em um processo psicoterapêutico, um princípio básico: a necessidade de se expor novamente o cliente, em circunstâncias mais favoráveis, a condições nas quais apareçam emoções com as quais ele não pôde lidar adequadamente no passado. Nas palavras de Alexander (1965, p. 83):

a fim de poder receber ajuda, ele deve passar por uma experiência emocional corretiva adequada para reparar a influência traumática de experiências anteriores. É de importância secundária se essa experiência corretiva tem lugar durante o tratamento ou na vida cotidiana do paciente.

Para Alexander (1965), a fim de que essa experiência emocional corretiva possa ter lugar, é preciso que o terapeuta adote uma 
atitude diferente daquela esperada pelo cliente, quer dizer, é importante que o terapeuta não se renda às repetições ou expectativas de repetições do cliente: "ainda que o cliente continue atuando em conformidade a pautas antiquadas, a reação do analista se adapta estritamente à situação terapêutica real" (p.83), o que ajudará o cliente, mais do que a ver, "a sentir a irracionalidade de suas reações emocionais" (p. 83). Dessa forma, "a atitude objetiva, compreensiva, do analista, permite ao paciente encarar de maneira diferente suas reações emocionais e fazer, assim, uma nova definição para o velho problema" (p.84). O essencial aqui é que a reação do terapeuta ante seu cliente é diferente da reação esperada pelo cliente, uma expectativa que, por sua vez e via de regra, se baseia nas respostas habituais do ambiente do cliente, desde a infância. Dessa forma, não é o cliente como um todo que é deliberadamente frustrado, mas, sim, algumas de suas expectativas, exatamente aquelas que sustentam sua neurose e seu sofrimento. Fritz Perls foi um mestre na arte de provocar esse tipo de frustração, como podemos ver nos vídeos de seus trabalhos terapêuticos e em muitos de seus textos.

Alexander (1965, p. 84) enfatiza também que somente a compreensão intelectual desse esquema não basta, pois a mudança só se dá "mediante a experiência real na relação entre paciente e terapeuta". Nessa relação, é necessário que o terapeuta tenha uma compreensão clara sobre seu cliente, de maneira a que possa perceber quando se reativam no cliente vivências anteriores e, assim, proporcionar "mediante sua própria atitude, as novas experiências necessárias para gerar resultados terapêuticos". Essa atitude do terapeuta deve ser cuidadosamente conscientizada, de modo a evitar um certo tipo de espontaneidade, uma vez que há o risco de "repetir a impaciência do genitor ou a solicitude que originaram a neurose, e, assim, não constituir a experiência corretiva necessária para a cura" (Alexander, 1965, p. 85). Nesse sentido, na abordagem gestáltica diríamos que é necessário confrontar o cliente, tomando muito cuidado, quanto a o quê e quanto de sua reação o terapeuta pode demonstrar para o cliente na situação terapêutica. Como bem lembra Quattrini (2004, p. 60):

deixar transparecer não significa deixar transparecer o todo. [...] E se não se trata do todo, a questão será escolher e o parâmetro deverá ser congruente com a situação: em uma determinada situação terapêutica será necessário escolher aquilo que seja mais de acordo com a mesma. Que é que faz bem ao paciente?

Alexander (1965, p. 86) lembra que essa experiência emocional corretiva não produz resultados imediatos e certos, pois é bem conhecida em psicanálise "a tormenta que precede a calma", ou seja, 
o fato de que "toda vez que o tratamento ataca um sintoma ou atitude neurótica, se produz geralmente um recrudescimento do sintoma, antes que o paciente possa abandoná-lo por completo".

Alexander (1965, p. 87) levanta também que caberia colocar-se em dúvida se uma só experiência, a experiência do encontro terapêutico, poderia desfazer os efeitos acumulados de um mal que se construiu durante anos. Responde, dando testemunho do "tremendo efeito que tem sobre jovens delinqüentes o mero fato de a atitude do terapeuta não seja crítica e moralista, mas, pelo contrário, a de um amigo benévolo e desejoso de ajudá-los". Realçando ainda mais a importância dessa experiência que chama de "emocional corretiva", Alexander (1965, p. 87) afirma que, para algumas pessoas, "os marcantes contrastes entre suas próprias reações autocríticas e superegóicas, e a atitude tolerante do analista, pode bastar por si só para produzir resultados profundos". Mais tarde, Carl Rogers (apud SANTOS, 1982, p. 60), teorizando sobre a postura do terapeuta em um processo de terapia, afirma, em consonância com Alexander, que o cliente,

\begin{abstract}
ao verificar as atitudes de consistência e de consideração positiva e incondicional do terapeuta, passa a tomar as mesmas atitudes para consigo, aceitando-se e reconhecendo-se tal como é e, portanto, pronto a mover-se para a frente, no processo de amadurecimento. Sente-se capaz de retirar as fachadas que tem usado, eliminar certas defesas e abrir-se ao que realmente é.
\end{abstract}

Como afirmei no início deste artigo, e como já dei a perceber, há nas reflexões e na proposta de Alexander sobre esse aspecto da relação terapêutica alguns pontos de aproximação com a proposta gestáltica. Essas aproximações não nos devem, no entanto, fazer perder de vista que há também diferenças importantes - chego mesmo a pensar que Alexander, preso ao olhar psicanalítico da época, provavelmente não se deu conta de que há, na proposta que faz, elementos que ele não aprofundou suficientemente. Alguns desses elementos, mais tarde, foram tratados e ampliados por autores da psicologia fenomenológico-humanista, como Perls e Carl Rogers.

Algumas das mais notáveis diferenças entre a proposta de Alexander e a proposta gestáltica, e que justificam a mudança do conceito de experiência emocional corretiva para o de experiência emocional atualizadora, se apoiam na maneira como se compreende a neurose e, por via disso, a própria psicopatologia.

Para Alexander (1965, p. 16), "toda neurose e toda psicose representam um fracasso do ego no cumprimento de sua função de assegurar gratificação adequada às necessidades subjetivas, segundo as condições exteriores existentes". Para o autor, essa definição vale para todo tipo de perturbação mental, sejam as de origem corporal (derivadas de questões "mecânicas, infecciosas, tóxicas ou 
degenerativas") ou as "que se desenvolvem como resultado de experiência traumáticas", sendo que, no caso dessas últimas, "a psicoterapia trata de restabelecer esta capacidade do ego por meios psicológicos."

Quero ressaltar nessa definição de Alexander, de cunho psicanalítico, aquela que é a grande diferença ante um olhar gestaltista para a neurose e a psicose: a neurose e a psicose não são encaradas, numa abordagem fenomenológica, como "um fracasso" da pessoa na gratificação adequada de suas necessidades, mas, ao contrário, como um sucesso, na medida que representa a maneira mais criativa que a pessoa conseguiu para manter sua integridade. Ou, nas palavras de Pimentel (2003, p. 51),

a função dos mecanismos neuróticos, na teoria da Gestaltterapia, é uma função saudável, constituindo um modo de auto-regulação que, embora impedindo que o ciclo figurafundo seja permanentemente renovado, permite que o seu funcionamento seja possível.

Se buscarmos nos fundamentos da Gestalt-terapia, encontraremos em Perls (1977b, p. 45) uma definição relacional para a neurose, ou seja, a compreensão da neurose como proveniente da relação do homem com seu ambiente, o qual, na neurose, influi demasiadamente sobre o ser humano. Para Perls, a neurose é "uma manobra defensiva para protegê-lo contra a ameaça de ser barrado por um mundo esmagador. Trata-se de sua técnica mais efetiva para manter o equilíbrio e o sentido de auto-regulação numa situação em que sente que as probabilidades estão contra ele".

Perceba que Perls trata a neurose como uma "manobra defensiva" e "sua técnica mais efetiva para manter o equilíbrio e o sentido de auto-regulação", ou seja, a neurose é um sucesso.

Sérgio Buarque (2007, p. 160), comentando a abordagem gestáltica sobre a neurose, diz que uma das principais contribuições dessa abordagem é

a genial noção de neurose como 'distúrbio do crescimento' pessoal e não defeito de personalidade, (o que) altera, na sua essência, a idéia anteriormente vigente de uma estrutura defeituosa ou de uma tipologia neurótica. Prevalece então a idéia de disfunção, que, pela contextualidade dinâmica e contínua, não se repete e sim se recria a cada instante. É aí que se percebe a pessoa podendo também a cada instante ser trabalhada. Rompe-se 0 mito do trauma como acontecimento original, o bigue-bangue transformador da psicoterapia numa 'arqueologia'.

Idêntico raciocínio vale para a psicose, muito embora nela as perdas na qualidade do contato sejam, obviamente, mais severas. 
A compreensão da neurose como um sucesso deriva, em Gestaltterapia, da influência de Kurt Goldstein sobre o casal Perls no início de sua formação e também da compreensão do que é um ajustamento criativo.

Na visão da Gestalt-terapia, o ser humano é um ser em relação, é um ser inserido num campo organismo-meio, é um ser que age criativamente num meio. Ajusta-se ao meio e ajusta o meio a si, numa infinita troca. O bom ajustamento é o chamado "ajustamento criativo", ou seja, ele se baseia em um diálogo entre a novidade e a conservação, o que permite uma reestruturação, ou seja, permite que algo novo seja assimilado ao velho, gerando uma nova configuração. É através de ajustamentos criativos que a pessoa pode superar o que já não é funcional, sem negar a importância do vivido, mantendo-se um constante processo e em constante ampliação de sua autonomia, dentro das possibilidades que encontra em seu ambiente (TELLEGEN, 1984, p. 45). Perls (apud JACOBS, 1997, p. 97) define o ajustamento criativo como "um relacionamento entre pessoa e meio no qual a pessoa com responsabilidade contata, reconhece e lida com seu espaço de vida e se responsabiliza por criar condições que a conduzam ao seu próprio bem-estar." É o ajustamento criativo que permite a uma pessoa aproximar-se ao máximo que possa de contatos nutritivos e afastar-se ao máximo que possa de contatos tóxicos, em sua perene busca pelo desenvolvimento de seus potenciais.

Sob o olhar gestáltico, a neurose é uma maneira de ajustamento criativo, ou seja, é a melhor configuração que a pessoa conseguiu alcançar para continuar a se desenvolver, mesmo que o ritmo de seu crescimento tenha que ser diminuído. Ao se neurotizar para sobreviver em um ambiente hostil, a pessoa se defende e preserva sua capacidade de crescimento e se mantém em um estado de emergência crônica de baixa intensidade até que possa ou tenha que se movimentar e romper esse estado para enfrentar novas necessidades ou novos desafios que a vida lhe impõe. Em outros termos, podemos dizer que a neurose é uma maneira criativa de a pessoa manter vivo o processo de auto-atualização, a busca infindável de ser o que se é.

A neurose é uma dificuldade de atualização. Essa é a idéia mais clara da neurose do ponto de vista da Gestalt-terapia, ou seja, o neurótico não pôde atualizar-se como seria desejável, e, por isso, cristalizouse, quer dizer, ele repete, repete, repete um ajustamento que não dá mais certo porque anacrônico, embora, na origem, este ajustamento tenha sido providencial, salvador, pois foi a maneira mais criativa que o indivíduo teve para não sucumbir ante a pressão do ambiente. Agora, quando esse ajustamento se mostra dolorido, desatualizado, ele precisa ser refeito, atualizado, mas não corrigido. Dentre outros motivos para que não se pense em corrigir, posso citar, de momento, 
- fato de que, se pudesse voltar atrás, a pessoa faria tudo novamente do mesmo jeito, e faria tudo novamente do mesmo jeito porque esse jeito foi, à época, o ajustamento mais criativo que ela pôde fazer. Esse ajustamento foi tão bem feito à época, que permitiu à pessoa chegar agora até o terapeuta para pedir ajuda, ou seja, a pessoa sobreviveu e manteve presente sua capacidade de criar, a mesma capacidade que hoje Ihe possibilita perceber a dor e procurar ajuda para voltar a se atualizar de uma maneira menos cristalizada. Desta forma, não há o que corrigir, há o que atualizar.

O conceito de auto-atualização é básico para a compreensão da neurose do ponto de vista da abordagem gestáltica, embora haja aí alguns problemas quanto a traduções do inglês para o português. Goldstein (2001) usa em seu livro o termo "Self-actualization", o qual, em português, muitas vezes é traduzido por "auto-regulação", e não "auto-atualização". Como prefiro a segunda tradução e não quero modificar textos publicados em português, compreenderei aqui as duas expressões como equivalentes.

Para Goldstein (1966, p. 201), "há só um motivo pelo qual os seres humanos se movem: a tendência à auto-atualização". Goldstein diz ainda, baseado nas observações que fez em seus pacientes, que eles "não podem se auto-atualizarem sem respeitarem seu entorno em alguma medida, especialmente as outras pessoas". Para Goldstein (1966, p. 203), "a auto-atualização de uma pessoa só pode ser alcançada através de alguma renúncia em favor de alguém, e da solicitação de renúncias por parte de outros".

Nessa troca de ganhos e de renúncias que caracteriza as relações humanas e as relações do ser humano com seu ambiente, a cada momento a pessoa alcança a melhor configuração que pode, a fim de manter-se crescendo. E aqui temos outra diferença quanto ao conceito de Alexander sobre a neurose e a psicose: enquanto Alexander, por causa de seu referencial psicanalítico da época, se fundamenta em uma psicopatologia de conflito e defesa, uma abordagem fenomenológico-humanista, embora não descarte a importância desse olhar, privilegia a compreensão da neurose como um problema de desenvolvimento, como, aliás, já vimos em Buarque (2007).

Explicando o que é um modelo de conflito e defesa, Jacobs (1997, p. 147), afirma que neste modelo compreendem-se as desordens emocionais como basicamente internas e derivadas de "conflitos entre impulsos, ou de conflitos entre impulsos e o princípio de realidade do ego, assim como das defesas que surgem contra esses conflitos". Nesse olhar, se compreende o ser humano em sofrimento emocional como desejoso "de reter os impulsos infantis, desistindo deles com relutância para se adaptarem às demandas da realidade." Esse é o modelo que encontramos na definição de Alexander, citada acima, para a neurose. 
No outro modelo de compreensão do sofrimento emocional, o modelo desenvolvimentista, segundo Jacobs (1997, p. 147),

\begin{abstract}
as desordens surgem quando há um vínculo pobre entre as necessidades de desenvolvimento da pessoa e os recursos e as possibilidades do meio ambiente, resultando em interrupções no desenvolvimento, um processo de desenvolvimento que foi impedido de prosseguir.
\end{abstract}

A Gestalt-terapia, especialmente a Gestalt-terapia de Curta Duração, tem sua estratégia clínica fundamentada no modelo desenvolvimentista, uma vez que esse é o campo por excelência de uma psicoterapia fenomenológico-humanista. O próprio Perls (1997, p. 11), na apresentação à edição de 1969 do Gestalt-terapia, afirma que

a Gestalt-terapia agora está se tornando maior de idade, embora eu tenha escrito o manuscrito original, se tanto, há vinte anos. [...] A ênfase global, entretanto, mudou da idéia de terapia para um conceito gestáltico de crescimento (desenvolvimento). Agora considero a neurose não uma doença, mas um de vários sintomas de estagnação do crescimento (desenvolvimento).

Por causa dessa diferença na noção de psicopatologia, há importantes diferenças quanto à postura e a presença do terapeuta ante seu cliente e também diferenças quanto aos propósitos da própria psicoterapia. Como bem lembra Boainain (2007, p. 12), por ver o homem como "um ser em busca e construção de si mesmo, cuja natureza continuamente se desvela e exprime no realizar de suas possibilidades e na atualização de seu potencial, compreendem os humanistas que só se é pessoa, só se é realmente humano, no autêntico, livre e integrado ato de se desenvolver". Daí decorre, na psicologia fenomenológico-humanista, a compreensão da natureza humana "como algo fluido: uma tendência para crescer, um movimento de sair de si, um projetar-se, um devir, um incessante tornar-se, um contínuo processo de vir-a-ser."

É a partir dessa compreensão de homem que Ribeiro (1999, p. 135) pode afirmar que a finalidade prioritária (embora não única) da Gestalt-terapia de Curta Duração é a de "liberar as forças preservadas da personalidade e não a de debelar sintomas". Segundo este autor, num processo de Gestalt-terapia de Curta Duração, o que se busca é facilitar à pessoa que reencontre "sua capacidade de fluir, de ser espontânea, porque essas capacidades pertencem à natureza da pessoa, pois provêm de um mecanismo inato no ser humano, que é o de auto-regular-se".

Decorre, então e também, dessa diferença quanto à compreensão da psicopatologia nossa de cada dia a impossibilidade para os gestaltistas de utilizarem 0 conceito de experiência emocional 
corretiva de Alexander, sendo necessário compreendê-lo como experiência emocional atualizadora, uma vez que o sofrimento neurótico implica em que o desenvolvimento precisa ser retomado em um ritmo melhor, ser atualizado, e não corrigido.

Outro ponto em que, me parece, a Gestalt-terapia avança para além da proposta de Alexander diz respeito ao como se dá essa relação terapêutica que pretende provocar no cliente uma experiência emocional atualizadora. Embora as idéias de Alexander tenham a virtude de já trazer em seu bojo um avanço quanto ao excessivo privilégio dado à transferência na psicanálise mais clássica, ainda lhe falta uma questão que para os gestaltistas é primordial: a relação terapêutica é algo que se dá entre o terapeuta e seu cliente, e não algo que o terapeuta vá proporcionar ao cliente.

Para Perls, Hefferline e Goodman (1997, p. 36),

a situação terapêutica é mais do que somente uma ocorrência estatística de um médico mais um paciente. É o encontro de médico e paciente. $O$ médico não será um bom terapeuta se for rígido e insensível às necessidades específicas de uma situação terapêutica que está sempre mudando. [...] (O médico) Não é um terapeuta se se recusa a ser parte dos processos em andamento na situação psiquiátrica. Do mesmo modo, o comportamento do paciente é ditado por muitas variáveis da entrevista, e somente os $100 \%$ rígidos ou dementes (esquecidos do contexto no qual operam) comportar-se-ão no consultório como se comportam fora dele.

Perls, Hefferline e Goodman descrevem a situação terapêutica como diretamente derivada da interação do organismo com o ambiente, não os dois, organismo e ambiente, tomados em separado. Para facilitar que o cliente recobre sua awareness total e retome seu processo mais pleno de auto-atualização, a abordagem gestáltica toma a situação clínica como uma situação experimental (PHG, 1997, p. 37). Isso quer dizer que é preciso que o terapeuta se engaje na situação terapêutica, que ele se lembre de que se é a experiência de cada situação vital o que possibilita o sentimento da própria existência e da existência do outro e do ambiente, isso igualmente é válido para a situação clínica. Nela, o terapeuta faz e é feito pela situação, tanto quanto seu cliente.

Dessa maneira, podemos conceber a psicoterapia como uma situação que vai proporcionar ao cliente a experiência de buscar a criação de novas respostas ajustadas criativamente ao caráter novo da situação. No dizer de Perls (1977b, p. 113), que se aproxima bastante, nesse aspecto, do dizer de Alexander, 
se mudarmos a atitude do paciente em relação ao comportamento de interromper que ele apresenta no consultório, sua atitude mudada eventualmente se expandirá e abarcará seu estilo, natureza, seu modo de vida. Seu comportamento aqui e agora é um corte microscópio de seu comportamento total. Se ele vir como é estruturado o seu comportamento na terapia, verá como o estrutura no cotidiano.

Essa postura diante da situação clínica, essa atenção a como se desenrola o encontro terapêutico a cada sessão, leva a uma percepção mais acurada do que está ali, e a uma disponibilidade mais generosa para o que está ali. Isso quer dizer que, atento ao que acontece, o terapeuta se liberta de uma postura que poderia deixar implícita uma exigência de que algo devesse estar ali. Com isso, o acolhimento ao cliente, a possibilidade da empatia, da compaixão e da inclusão se fazem mais claramente presentes na situação clínica, o que, por sua vez, possibilita mais consistentemente que o cliente possa fazer dessa situação e dessa relação uma experiência emocional atualizadora.

\section{Referências Bibliográficas}

ALEXANDER, F.; FRENCH T. Terapeutica Psicoanalitica. Buenos Aires, Argentina: Editorial Paidós, 1965.

BELLAK, L.; SMALL L. Psicoterapia de Emergência e Psicoterapia Breve. Porto Alegre: Artes Médicas, 1980.

BOAINAIN J r, Elias. O Estudo do Potencial Humano na Psicologia Contemporânea: A corrente humanista e a corrente transpessoal. Centro de Estudos e Encontro da Abordagem centrada na Pessoa Disponível em: http://www.encontroacp.psc.br/estudo.htm, acesso em 18 set. 2007.

BRAIER, E. A. Psicoterapia Breve de Orientação Analítica. São Paulo: Martins Fontes, 1986.

BUARQUE, Sérgio. Neurose. In: D'ACRI, G., LIMA, P.; ORGLER, S. Dicionário de Gestalt-terapia:Gestaltês. São Paulo: Summus, 2007, p. 158-160.

D'ACRI, G.; LIMA, P.; ORGLER, S. Dicionário de Gestaltterapia:Gestaltês. São Paulo: Summus, 2007.

FERREIRA-SANTOS, E. Psicoterapia Breve: Abordagem sistematizada de situações de crise. São Paulo: Ágora, 1997.

FIORINI, H. J. Teoría y Técnica de Psicoterapias. Buenos Aires: Ediciones Nueva Visión, 1975.

GILLIÉRON, E.As Psicoterapias Breves. Rio de Janeiro: Jorge Zahar Editor, 1986. 
Fontes, 2004.

GOLDSTEIN, K. Human Nature in the Light of Psychopathology. New York: Schocken Books, 1966.

HYCNER, R.; J ACOBS, L. Relação e Cura em Gestalt-terapia. São Paulo: Summus, 1997.

LEMGRUBeR, V. Psicoterapia Focal: o efeito carambola. Rio de J aneiro: Revinter, 1995.

PERLS, F. S. Gestalt-terapia Explicada(Gestalt therapy verbatim).

São Paulo: Summus, 1977.

PERLS, F. S. A Abordagem Gestáltica e Testemunha Ocular da Terapia. Rio de Janeiro: Zahar Editores, 1977.

PERLS, F. S.; HEFFERLINE, R.; GOODMAN, P. Gestalt-terapia. São Paulo: Summus, 1997.

PIMENTEL, A. Psicodiagnóstico em Gestalt-terapia. São Paulo: Summus, 2003.

PINTO, E. B. Gestalt-terapia de Curta Duração para Clérigos Católicos: Elementos para a prática clínica. 2007. 257 f. Tese (Doutorado em Ciências da Religião) - Pontifícia Universidade Católica de São Paulo, São Paulo.

Psicoterapia de Curta Duração na Abordagem Gestáltica: Elementos para a prática clínica.São Paulo: Summus, 2009.

QUATTRINI, P. O Trabalho da Gestalt na Escola de Florença. Revista Sampa GT, São Paulo, ano 1, n. 1, p. 50-61, 2004.

RIBEIRO, J. P. Gestalt-terapia: refazendo um caminho. São Paulo: Summus, 1985.

$\overline{1} \overline{9} \overline{9} \overline{.}$

Gestalt-terapia de Curta Duração. São Paulo: Summus,

SANTOS, O. de B. Aconselhamento Psicológico \& Terapia: Autoafirmação, um determinante básico.São Paulo: Livraria Pioneira Editora, 1982.

TELLEGEN, T. A. Gestalt e Grupos: uma perspectiva Sistêmica. São Paulo: Summus, 1984.

YOSHIDA, E. M. P. Psicoterapias Psicodinâmicas Breves e Critérios Psicodiagnósticos. São Paulo: EPU, 1990.

\section{Endereço para correspondência}

Ênio Brito Pinto

Instituto de Gestalt de São Paulo, Rua J oão Cachoeira, 1735, CEP 04535-016,

Itaim-Bibi, São Paulo-SP, Brasil

Endereço eletrônico: eniobrito@uol.com.br

Recebido em: 06/04/2008

Aceito para publicação em: 25/03/2009

Editor responsável: Eleonôra Torres Prestrelo 


\section{Notas}

* Psicoterapeuta (gestalt-terapeuta) e doutor em Ciências da Religião pela Pontifícia Universidade Católica de São Paulo (PUC-SP). 